\title{
A novel vertebrate system for the examination and direct comparison of the relative biological effectiveness for different radiation qualities and sources
}

E. R. Szabó, Z. Reisz, R. Polanek, T. Tőkés, Sz. Czifrus, Cs. Pesznyák, B. Biró, A. Fenyvesi, B. Király, J. Molnár, Sz. Brunner, B. Daroczi, Z. Varga \& K. Hideghéty

To cite this article: E. R. Szabó, Z. Reisz, R. Polanek, T. Tőkés, Sz. Czifrus, Cs. Pesznyák, B. Biró, A. Fenyvesi, B. Király, J. Molnár, Sz. Brunner, B. Daroczi, Z. Varga \& K. Hideghéty (2018) A novel vertebrate system for the examination and direct comparison of the relative biological effectiveness for different radiation qualities and sources, International Journal of Radiation Biology, 94:11, 985-995, DOI: 10.1080/09553002.2018.1511928

To link to this article: https://doi.org/10.1080/09553002.2018.1511928

Published online: 17 Oct 2018.

Submit your article to this journal $\sqsubset$

Llll Article views: 38

View Crossmark data \lceil

Citing articles: 1 View citing articles $\square$ 


\title{
A novel vertebrate system for the examination and direct comparison of the relative biological effectiveness for different radiation qualities and sources
}

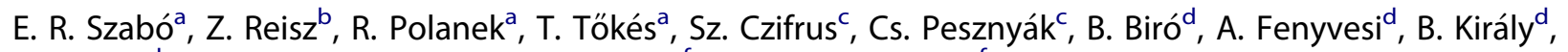 \\ J. Molnár ${ }^{d}$, Sz. Brunner ${ }^{a}, B$. Daroczi $^{e}$, Z. Varga ${ }^{f}$ and K. Hideghéty ${ }^{a, f}$ \\ ${ }^{a}$ Extreme Light Infrastructure - Attosecond Light Pulse Source, ELI-HU Non-Profit Ltd, Szeged, Hungary; ${ }^{b}$ Department of Pathology, \\ University of Szeged, Szeged, Hungary; 'Budapest University of Technology and Economics Institute of Nuclear Techniques, Budapest,

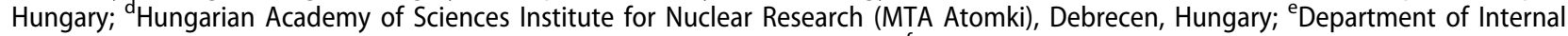 \\ Medicine, Division of Geriatrics, University of Debrecen, Debrecen, Hungary; 'Department of Oncotherapy, University of Szeged, \\ Szeged, Hungary
}

\begin{abstract}
Purpose: The recent rapid increase of hadron therapy applications requires the development of high performance, reliable in vivo models for preclinical research on the biological effects of high linear energy transfer (LET) particle radiation.

Aim: The aim of this paper was to test the relative biological effectiveness (RBE) of the zebrafish embryo system at two neutron facilities.

Material and Methods: Series of viable zebrafish embryos at 24-hour post-fertilization (hpf) were exposed to single fraction, whole-body, photon and neutron (reactor fission neutrons $(<\mathrm{En}=1 \mathrm{MeV}\rangle$ ) and $(p(18 \mathrm{MeV})+\mathrm{Be},<\mathrm{En}>=3.5 \mathrm{MeV})$ fast neutron) irradiation. The survival and morphologic abnormalities of each embryo were assessed at 24-hour intervals from the point of fertilization up to $192 \mathrm{hpf}$ and then compared to conventional $6 \mathrm{MV}$ photon beam irradiation results.

Results: The higher energy of the fast neutron beams represents lower RBE (ref. source LINAC 6 MV photon). The lethality rate in the zebrafish embryo model was 10 times higher for $1 \mathrm{MeV}$ fission neutrons and 2.5 times greater for $\mathrm{p}(18 \mathrm{MeV})+$ Be cyclotron generated fast neutron beam when compared to photon irradiation results. Dose-dependent organ perturbations (shortening of the body length, spine curvature, microcephaly, micro-ophthalmia, pericardial edema and inhibition of yolk sac resorption) and microscopic (marked cellular changes in eyes, brain, liver, muscle and the gastrointestinal system) changes scale together with the dose response.

Conclusion: The zebrafish embryo system is a powerful and versatile model for assessing the effect of ionizing radiation with different LET values on viability, organ and tissue development.
\end{abstract}

ARTICLE HISTORY Received 17 February 2018

Revised 6 July 2018

Accepted 14 July 2018

\section{KEYWORDS}

Zebrafish; relative biological effectiveness (RBE); linear energy transfer (LET); ionizing radiation

\section{Introduction}

In recent years, there has been a marked development of radiation techniques that have contributed to the improvement of cancer treatment outcome (Peeters et al. 2010; Allemani et al. 2015). Advanced photon delivery techniques with enhanced conformity and the rapidly growing installations of superconducting cyclotron/synchrotron-based particle therapy facilities have made hadron therapy available for an increasing number of cancer patients (Specht et al. 2015). Charged particle therapy leads to an increase in dose precision due to the energy deposition characterized by the Bragg peak. Further innovative radiation approaches including boron neutron capture therapy (BNCT, Barth et al. 2012), high power laser-driven pulsed, ultra-intense, very high energy electron therapy (VHEE, Schüler et al. 2017), medical microbeam irradiation (Bräuer-Krisch et al. 2015) and Boron Proton Fusion Enhanced Proton therapy (BPFEPT, Yoon et al. 2014) are under scientific evaluation in order to improve the therapeutic ratio. It is therefore essential to study the biological effects of the different ionizing radiation forms and to establish safe clinical applications. The biological properties of any type of radiation are derived from the energy deposition pattern, which defines the properties and amount of DNA damage and potential repair. The energy deposited per unit track linear energy transfer (LET) is measured in $\mathrm{keV} / \mu \mathrm{m}$. The relative biological effectiveness (RBE) is defined in relation to a reference photon irradiation and is influenced by many factors. High LET, and consequently high RBE, radiation combined with a high selectivity of dose deposition has tremendous advantages over low LET beams for the local control for radio-resistant, hypoxic tumors - even in critical anatomical location. One of the first large clinical scale attempts to use high RBE radiation was fast neutron therapy in the 70s and 80s (Specht et al. 2015). Highly contradictory results were obtained at these first generation neutron facilities and actually only four fast neutron facilities with improved delivery technique (3D planning, conformal/

CONTACT K Hideghéty katalin.hideghety@eli-alps.hu Extreme Light Infrastructure - Attosecond Light Pulse Source, ELI-HU Nonprofit Kft, Dugonics Tér 13, Szeged 6720, Hungary

Color versions of one or more of the figures in the article can be found online at www.tandfonline.com/irab

Copyright $@ 2018$ Taylor \& Francis Group LLC. 
intensity-modulated RT) offering fast neutron therapy (FNT) for patients with salivary gland tumors, sarcomas and malignant melanoma (Liao et al. 2014).

There is a growing worldwide interest in high-linear energy transfer (LET) therapy with new hadron therapy centers and the radiobiology data generated by neutron therapy could help to develop novel in vivo model system for investigation of the biological effects and to develop biologically guided treatment approaches. Furthermore, fast neutron experiments are also suitable for the proton RBE simulations in the Bragg peak region, as the majority of the ionization occurs as a result of the formation of recoil protons (Warenius et al. 1994; Jones et al. 2001). There has been a considerable amount of research performed to determine the required RBE to induce cell death, mainly with in vitro cell culture experiments. Rodent species (mice, rats) models have been established as in vivo examinations models using special quantitative and semi-quantitative endpoints. Van der Kogel et al. (2002) introduced the rat spinal cord model which was also used in larger animals (Medin et al. 2011). Gueulette et al. (2001) performed large intercomparison studies at different neutron sources using the Lieberkühn crypt test on mice, which was also applied for radiobiology investigation of charged particles (Uzawa et al. 2007). An important endpoint could be cataractogenesis as well because of the extreme sensitivity of the ocular lens to ionizing radiation (Ainsbury et al. 2016). Numerous experiments have been performed for determination of high-LET RBE in mice and rabbit models (Hamada and Sato 2016) using lens opacification as endpoint.

The purpose of this paper was to develop and validate a novel in vivo system for assessment of the biological effects of different radiation qualities using Zebrafish (Danio rerio) embryos as in vivo vertebrate models. The zebrafish has become a widely used organism for diverse preclinical investigations including genetic, pharmacological, developmental studies. This vertebrate model is an ideal test system as they have many positive attributes including easy laboratory care, good reproduction captivity, rapid embryonic development 3 days (Geiger et al. 2006; Hwang et al. 2007) and the embryos are optical transparent. Their genomes share major homology with the human genome, making them amenable for the study of various human diseases of oncogenic, neurodegenerative, hematopoietic and cardiovascular origin (Zon 1999; Amatruda et al. 2002; Daroczi et al. 2006; Hwang et al. 2007). Zebrafish have a full complement of vertebrate-specific organs of radiobiological interest, including a brain, eyes, spinal cord, vasculature and digestive, excretory and hematopoietic systems. The detection of organ perturbations in early life stage adults makes them ideal for evaluation of genotoxic stress caused by irradiation (Geiger et al. 2006). Furthermore, the zebrafish has wide tolerance regarding their maintenance (Daroczi et al. 2006) and transportation. The embryos do not require sterile conditions, like the cell cultures, and thus are better suited for radiobiological studies at non-hospital research radiation sources. In contrast to cell cultures, the embryos are whole organisms and can be used for the abscopal effect (Yasuda et al. 2017) and immunogenic reactions (Langheinrich 2003) investigation. Changes due to total body exposure can also be detected at microenvironmental organ level and the small size of embryos allows for radiobiological experiments at early developmental stage of a new radiation approach with beam size and beam direction restrictions. The zebrafish model has previously been established for radiation biology experiments and radioprotective agents have been tested with this system (Szabó et al. 2016). The present study uses the zebrafish embryo system to quantify the low LET and high LET radiationinduced damages at the total organism, at organ and at tissue level in order to establish a novel in vivo model for RBE determination of different high LET sources.

\section{Material and methods}

\section{Ethical statement, zebrafish maintenance and embryo handling}

Experiments were carried out using laboratory-bred strain (AB) zebrafish embryos. The proposed animal experimental protocol was approved by the Ethical Committee for the Protection of Animals in Scientific Research at the University of Szeged (XXXII./1838.2015) and the experiments were performed in accordance with the National Institutes of Health (Bethesda, MD, U.S.A) guidelines on the care and use of laboratory animals. Stable and high-quality embryo production was induced by regulated light/dark cycle (14 hours/ 10 hours) and frequent and diverse feeding, three times/day with dry commercial fish food and freshly hatched brine shrimp. Wild-type, male and female adult fishes were kept in separate tanks with a recirculating water system at an optimal temperature of $28.5^{\circ} \mathrm{C}$. The fishes ( 2 female and 3 male) mated in embryo collection tanks in the afternoon and spawning occurred at the beginning of the photoperiod.

Embryos were collected and washed with $0.1 \%$ methylene blue solution then sorted under a stereomicroscope (Stemi 508, Stand K LAB, Carl Zeiss). Fertilized eggs were transferred to a $10 \mathrm{~cm}$ Petri dishes containing $5 \mathrm{ml}$ E3 medium $(5 \mathrm{mM}$ $\mathrm{NaCl}, 0.17 \mathrm{mM} \mathrm{KCl}, 0.33 \mathrm{mM} \mathrm{CaCl}, 0.33 \mathrm{mM} \mathrm{MgSO}, 0.1 \%$ methylene blue) and maintained under normoxic conditions at $28.5^{\circ} \mathrm{C}$, according to standard operating procedures. Embryos in the pharyngula period ( $24 \mathrm{hpf}$ ) were exposed to $0-10.28$ Gy of high LET neutron irradiation and to $0-20$ Gy of reference $\gamma$ radiation beam.

The experiments were repeated three times at all visited centers, at the standard $28.5^{\circ} \mathrm{C}$ temperature, using a portable incubator (Ranger MX45, Lynd Products). Zebrafish embryos were used at the same stage of development and final assessment was performed at 168-hour post-irradiation (hpi).

\section{Irradiation}

\section{Photon radiation}

$6 \mathrm{MV}$ photons, generated by a linear accelerator (Primus2 Siemens, Department of Oncotherapy, University of Szeged), was used as a reference beam. The zebrafish embryos at 
(a)

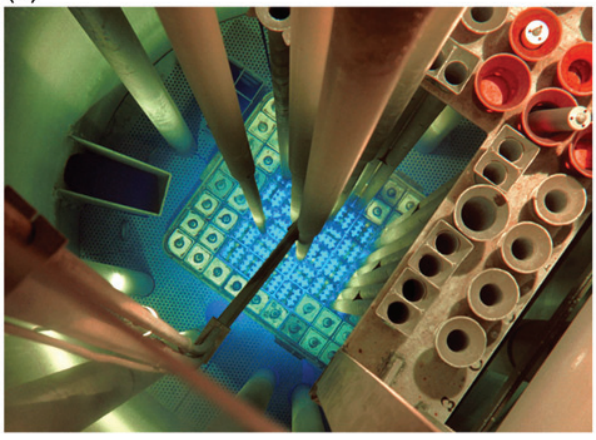

(b)

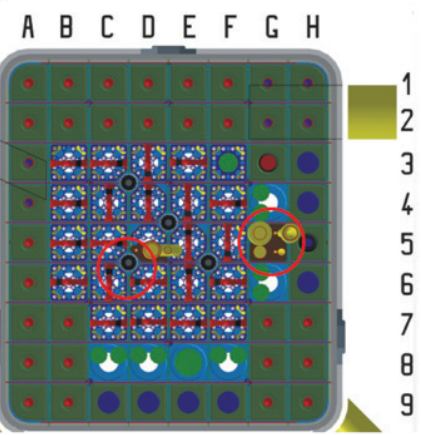

Figure 1. The Training Reactor of the Budapest University of Technology and Economics. (a) BME Training. Reactor core as seen from above during $100 \mathrm{~kW}$ power operation. (b) Layout of the reactor core and the 'pneumatic rabbit' system (red circles).

$24 \mathrm{hpf}$, were individually placed in a well within a 96-well plate, with $250 \mu \mathrm{l}$ embryo medium. The plates were positioned between two $2 \mathrm{~cm}$ polymethyl methacrylate (PMMA) slabs to assure a homogeneous radiation exposure. The isocenter was positioned in the plates' geometrical centers. Groups were treated at room temperature at $0 \mathrm{~Gy}, 5 \mathrm{~Gy}$, $10 \mathrm{~Gy}, 15 \mathrm{~Gy}, 20 \mathrm{~Gy}$ doses with a dose rate of $3 \mathrm{~Gy} / \mathrm{min}$ and a source to surface distance (SSD) of $100 \mathrm{~cm}$. The planned doses were delivered in two portions with half of the dose delivered upwards and the remaining downwards by means of a rotating gantry. The irradiation exposure experimental setup is given in our previous publication (Szabó et al. 2016). The embryos were continually assessed after irradiation for survival at 24-hour intervals up to 7 days for the generation of the survival curves and to detect the morphological abnormalities.

\section{Neutron irradiation facilities}

Neutron irradiation was performed at the Institute of Nuclear Technologies (NTI) of the Budapest University of Technology and Economics (BME) and at the cyclotron of the Hungarian Academy of Sciences Institute for Nuclear Research (MTA-Atomki).

BME irradiation was performed using the BME Training Reactor 'pneumatic rabbit' system. The outer diameter of the pneumatic polyethylene tube system is $25 \mathrm{~mm}$, the thickness of wall is $2 \mathrm{~mm}$ and the inner diameter is $21 \mathrm{~mm}$. In the center of the tube is a sample irradiation capsule, which is also made of polyethylene with a maximum sample mass of $30 \mathrm{~g}$. The capsule is $50 \mathrm{~mm}$ length and the diameter of capsule is $14 \mathrm{~mm}$. Irradiation time are possible from $2 \mathrm{~s}$ up to 2 hours and the delivery time is $3 \mathrm{~s}$. The pneumatic rabbit system has two types of connections: The 'quick' channel in the core of the reactor and the 'thermal' channel, in the water (Figure 1). All zebrafish irradiation occurred in the thermal channel. The power of the reactor during the experiment was $200 \mathrm{~W}$ and the irradiations lasted 36, 49, 63 and $72 \mathrm{~s}$.

The dose rate at the location of irradiation was calculated with the aid of the Monte Carlo transport code MCNP. Detailed 3-dimensional models of the entire core of the training reactor were set up, which were later used, among others, for coupled neutron-photon calculations in order to determine the dose rate. The Monte Carlo model has been validated using neutron flux and dose rate measurements in and near the reactor core.

According to the calculations, the dose rate of the neutrons and photons (gamma-radiation) at the place of the irradiation is $1.27 \pm 0.04 \mathrm{~Gy} / \mathrm{min}$. Accordingly, the dose delivered during the experiments were approximately between 0.76 and $1.52 \mathrm{~Gy}$ for the $36 \mathrm{~s}$ and $72 \mathrm{~s}$ long irradiations, respectively. The standard deviation of the calculated dose rate only refers to the Monte Carlo uncertainty and does not include modeling and cross-section based uncertainties and based on the previous experience of the authors and the literature, the real uncertainty is estimated at $0.14 \mathrm{~Gy} / \mathrm{min}$.

Three irradiation experiments were performed at MTA Atomki. The irradiation arrangement at the $\mathrm{p}(18 \mathrm{MeV})+\mathrm{Be}$ neutron source is shown in Figure 2. The zebrafish embryos, floating in solutions in Eppendorf tubes, were exposed to the mixed neutron-gamma field of the $\mathrm{p}(18 \mathrm{MeV})+\mathrm{Be}$ fast neutron irradiation facility (Fenyvesi András 2004) based on the MGC$20 \mathrm{E}$ cyclotron. During each experiment, $E_{p}=18 \mathrm{MeV}$ $\pm 0.3 \% \mathrm{MeV}$ energy protons beams were transported to the irradiation facility. The beam currents were in the $I_{p}=(9.2-10.7) \mu A$ range and they were kept constant during irradiation. The protons passed first a stainless steel entrance window foil and then a layer of flowing helium gas that cooled the bombarded target surface. The average energy loss of the protons was $\left\langle\Delta \mathrm{E}_{\mathrm{p}}\right\rangle=0.355 \mathrm{MeV}$ before reaching the beryllium target that fully stopped the beam. The protoninduced nuclear reactions on ${ }^{9} \mathrm{Be}$ target nuclei lead to emission of neutrons and gamma photons with continuous broad energy spectra that covered the $E=0-20 \mathrm{MeV}$ energy range. Most neutrons were emitted in the $E_{n}>0.1 \mathrm{MeV}$ energy range and the average neutron energy was $\left\langle E_{n}>=3.5 \mathrm{MeV}\right.$.

The irradiation field was monitored by a twin ionization chamber technique (Broerse et al. 1981) using thimble type EXRADIN T2 and M2 chambers with $3 \mathrm{~mm}$ thick build-up caps.

The $D_{\mathrm{n}}$ neutron and $D_{\gamma}$ gamma doses and the $D_{\text {tot }}=D_{\mathrm{n}}+D_{\gamma}$ total doses were calculated for water. The ratio of the neutron and gamma doses for the irradiated samples depended on the irradiation circumstances and on the position and environment of the samples (beam focusing, irradiation arrangement, neutron- and gamma-scattering, etc.). $\quad D_{\gamma} /\left(D_{\mathrm{n}}+D_{\gamma}\right)=(14 \pm 3) \quad \%$ ratios were obtained depending on the sample. The total dose rate was $\mathrm{dD}_{\text {tot }} /$ $\mathrm{dt}=(2.2-2.8)^{*} 10^{-3} \mathrm{~Gy} / \mathrm{s}$ depending on the irradiation run 
(a)

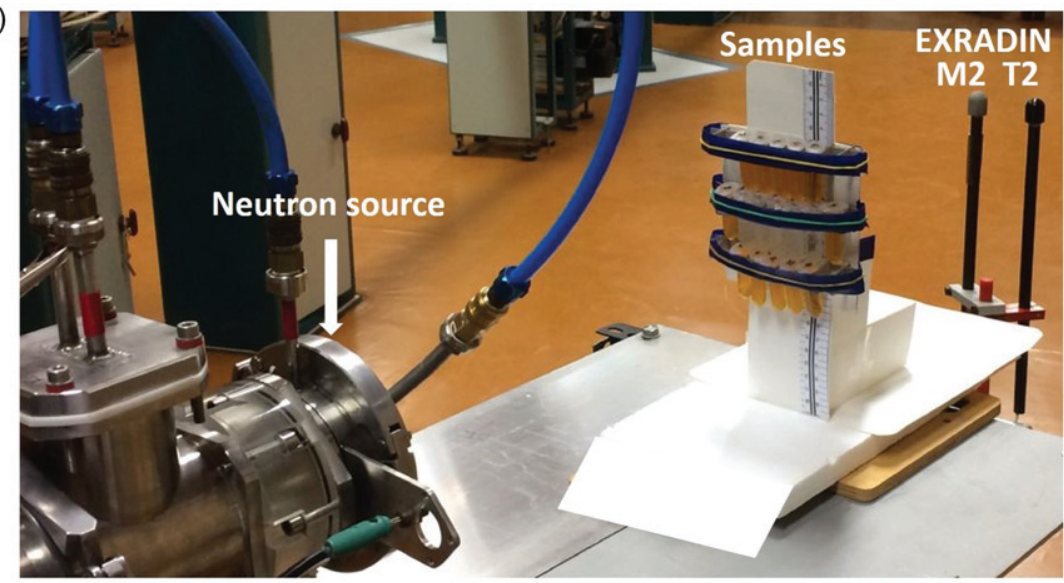

(b)

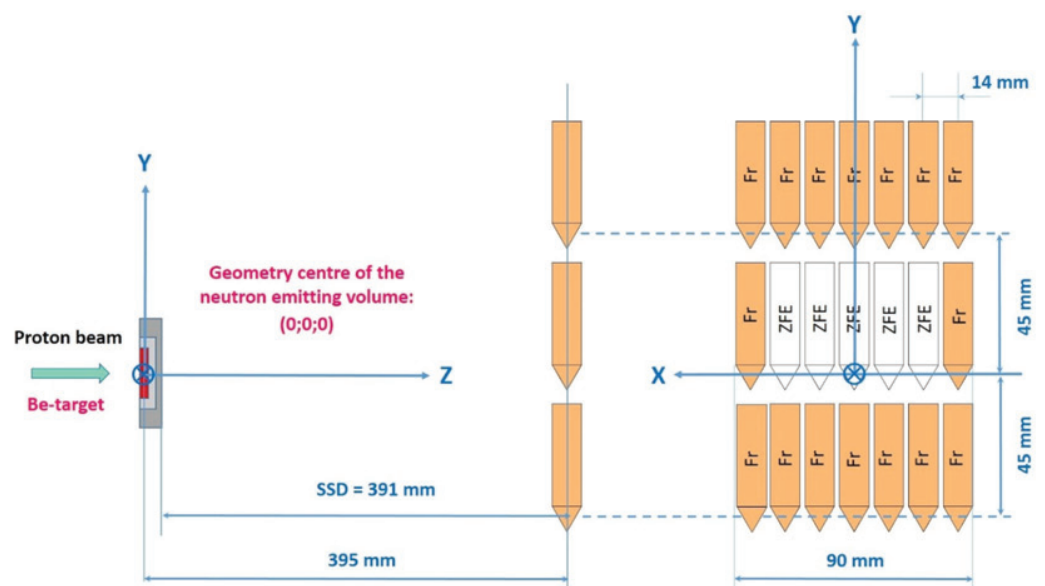

Figure 2. The irradiation arrangement at the $p(18 \mathrm{MeV})+B$ e neutron source. (a) The samples and the absorbed dose monitoring twin ionization chambers (EXRADIN T2 and M2) at the $\mathrm{p}(18 \mathrm{MeV})+$ Be neutron source of MTA Atomki. (b) The irradiation positions of the zebrafish embryos (ZFE) and the chemical dosimeter solutions (Fr) are shown in the sketch of the arrangement.

and the position of the sample in the irradiation arrangement.

\section{Analysis of treatment effects on morphology and survival}

Figure 3 shows the more severe morphological disorders, like pericardial edema and the spine curvature, which were recorded and evaluated as the biological endpoint for the RBE definition. Immediately after irradiation treatments with neutron sources, the $24 \mathrm{hpf}$ embryos from the Eppendorf tubes were placed in 96-well plates and were regularly observed throughout the day for a 7 day period. Similar observations were made for the reference photon irradiation. The observation period was executed without any manipulation apart from the addition of fresh embryo medium into the wells in every alternate day. Embryos were cultured at $28 \pm 1{ }^{\circ} \mathrm{C}$ with 14-h light/10-h dark cycle during the detection period. The developmental status of the embryos, the viability and morphology were regularly assessed from the time point fertilization up to $192 \mathrm{hpf}$, using a light transmission inverted microscope (Zeiss Axio Imager Z1) at $10 \times$ and $20 \times$ magnification and photomicrographs were recorded (AxioCam MR5 camera) for the deformed specimens representative. For the first $24 \mathrm{hpf}$, when the embryos were sorted into experiments, survival was defined through the assessment of cell division proper to developmental stages. The criterion for embryonic survival was the presence of cardiac contractions. The survival and the morphological abnormalities were evaluated using a total of 4.608 embryos in the proportion of the living individuals as follows:

Survival rate $\%=\frac{\text { the number of survived embryos }}{\text { the total number of embryos }} \times 100 \%$ Malformation rate $\%$

$$
=\frac{\text { the number of malformed embryos }}{\text { the total number of survived embryos }} \times 100 \%
$$

\section{Histopathology and tissue morphology evaluation}

Histological examinations were performed on the last day of every experiment observation, 7 days after irradiation. The embryos were anesthetized using a 1:100 dilution of $4 \mathrm{mg} / \mathrm{ml}$ tricaine methanesulfonate (Sigma Aldrich) and placed in $4 \%$ paraformaldehyde for a minimum 3 days fixation. The samples were embedded in paraffin from which $4 \mu \mathrm{m}$ thickness of sections were taken and stained with hematoxylin-eosin $(\mathrm{H} \& \mathrm{E})$, mounted on glass slides. All sections were analyzed by a Nikon Eclipse TS100 microscope (Nikon Americas, Inc.) at $10 \times, 20 \times$ magnification and scanned with Pannoramic 
(a)

$200 \mu \mathrm{m} \quad 7 \mathrm{dpf}-$ control

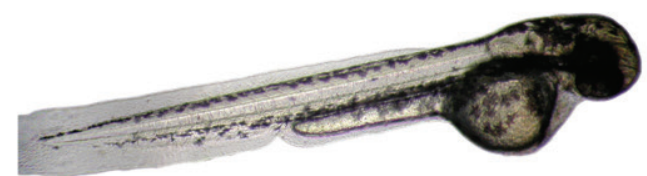

(c)

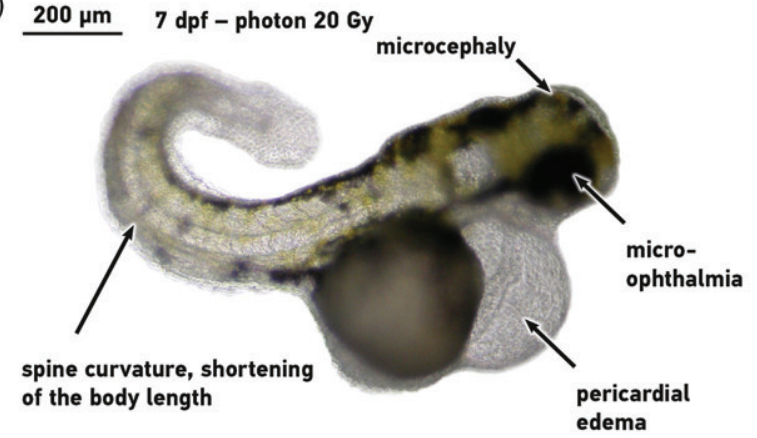

(b)
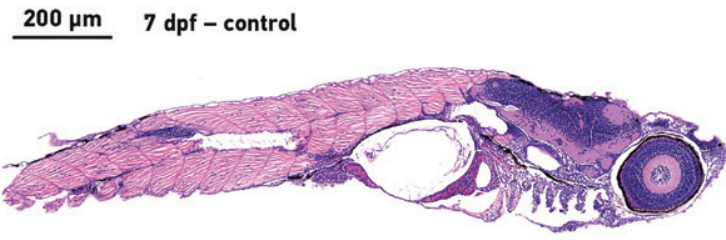

(d)

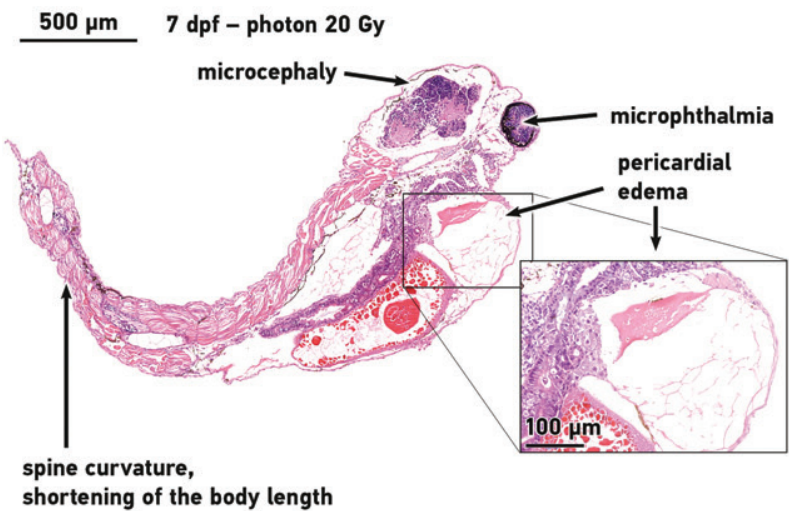

Figure 3. Morphologic effects of ionizing radiation. Appearance of control embryos (a, b) and ionizing radiation induced morphological abnormalities (c), histological tissue alterations (d) in a $20 \mathrm{~Gy}$ treated zebrafish embryo at 7 days post irradiation. Micrographs were taken of representative embryos at $10 \times(\mathrm{a}, \mathrm{b}, \mathrm{c})$ and $5 \times(d)$ magnification.

MIDI digital slide scanner (3D-HISTECH Ltd., Budapest). Representative images were analyzed for evaluation and recorded using the Pannoramic Viewer 1.14.50 RTM 3DHISTECH, from each treatment group at least 15 embryos were observed with the program.

\section{Statistical analysis}

All experiments were performed three times with 96 embryos $(n=96)$ in each experimental group. Data analysis was performed with the statistical software package GraphPad Prism Version 7.03 Windows. In the figures, values were expressed as mean \pm standard deviation (SD) of the three individual assay, $p$ values $<.05$ were considered significant. Log-rank test with Bonferroni correction were applied for the comparison of survival curves. To statistically determine significant differences between distorted groups, Chisquare test was performed.

\section{Results}

\section{Survival end point for RBE definition}

Preliminary studies were performed in preparation for irradiation experiments at neutron facilities, located some hundred kilometers from our core Institution. The dose-dependent reactions, the tolerance of the embryos to long transportation, in different holders, i.e. in closed Eppendorf tubes and at industrial circumstances were all tested at the Budapest Research Reactor (BRR) of Atomic Energy Research Institution (KFKI). These studies guided the large experimental campaign and thereafter the repeated RBE investigation including more than 4500 embryos irradiated with neutrons and $\gamma$ rays were performed.
Embryos were held until 7 days post-irradiation (dpi) (4 days after hatching) and survival statistics were made on the fraction of embryos still alive. Survival was $90-100 \%$ for mock irradiated embryos. Survival rates declined from the $4^{\text {th }} \mathrm{dpi}$, with an increasing level of neutrons exposure resulting in an acceleration of the process (Figure 4). On the last observation day $\left(7^{\text {th }} \mathrm{dpi}\right)$, significant differences were detected and $p>.0001$. This decay and trend were also detected in the $\gamma$ rays data but started one day later.

The analysis of the survival curves with Log-rank test resulted in $\mathrm{LD}_{50 / 7}$ values of $2 \mathrm{~Gy}$ for fission neutrons, $8.12 \mathrm{~Gy}$ for cyclotron neutrons and $20 \mathrm{~Gy}$ for $\gamma$ rays respectively.

$$
\begin{gathered}
\mathrm{RBE}=\frac{6 \mathrm{MeV} \text { photon } \mathrm{LD}_{50 / 7}}{1 \mathrm{MeV} \text { fission neutron } \mathrm{LD}_{50 / 7}}=\frac{20 \mathrm{~Gy}}{2 \mathrm{~Gy}}=10 \\
\mathrm{RBE}=\frac{6 \mathrm{MeV} \text { photon } \mathrm{LD}_{50 / 7}}{\mathrm{p}(18 \mathrm{MeV})+\text { Be fast neutron } \mathrm{LD}_{50 / 7}}=\frac{20 \mathrm{~Gy}}{8.12 \mathrm{~Gy}}=2.5
\end{gathered}
$$

The ratio of the $\mathrm{LD}_{\mathrm{n} / 50 / 7}$ for fission neutrons and $\mathrm{LD}_{\gamma / 50 / 7}$ photon beam provided an RBE of 10 and for $\mathrm{LD}_{\mathrm{n} / 50 / 7} 18 \mathrm{MeV}$ neutrons and $L D_{\gamma / 50 / 7}$ reference photons of 2.5 (Figure 4.).

\section{RBE determination by malformation analysis}

A simplified approach was applied for the recording of any visible developmental retardation, or morphological changes (micro-ophthalmia, spine curvature, pericardial edema) of the living embryos (Figure 5.). The distortion assessment on the $4^{\text {th }}$ and $5^{\text {th }}$ dpi provided evaluable data for different radiation quality comparison which has a good agreement with the survival based calculation. However, an exact definition of RBE is not possible using 24 hours observation periods, because of the steep dose distortion curve elevation of each radiation modality from $4^{\text {th }}$ to $5^{\text {th }} \mathrm{dpi}$. From the $6^{\text {th }}$ post-irradiation day the decreasing number of viable 
(a)

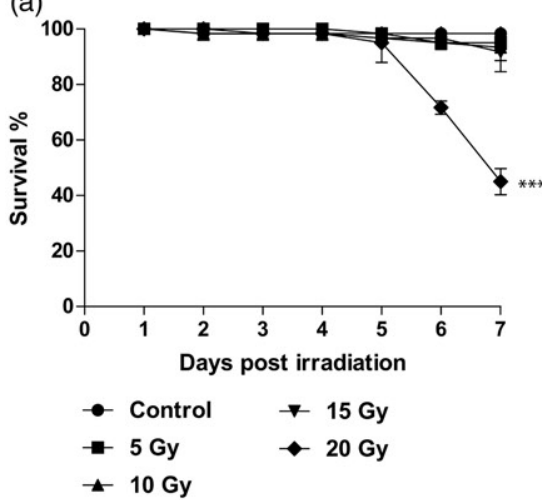

(b)

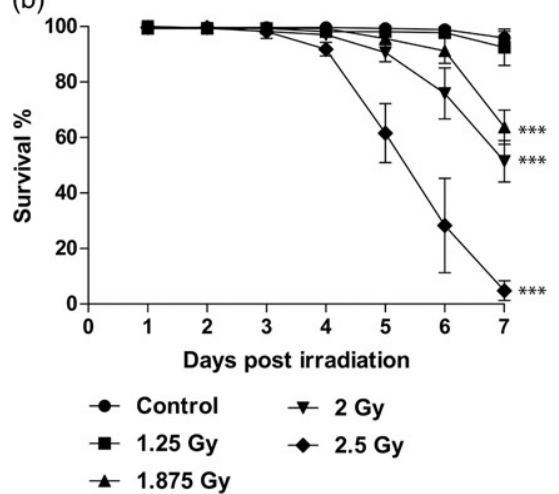

(c)

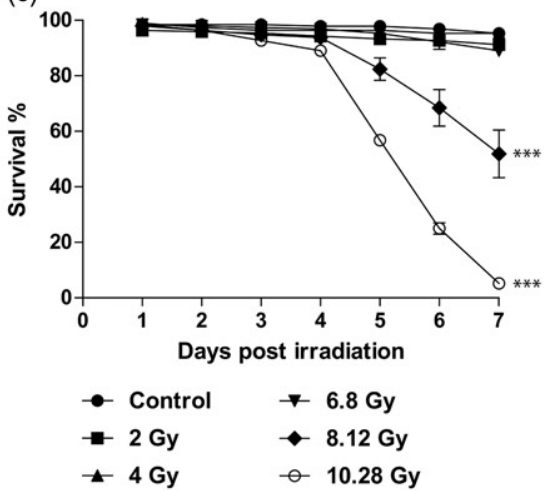

Figure 4. Dose dependent survival curves of zebrafish embryos. (a) Embryos at 24 hour post-fertilization (hpf) were exposed to conventional photon with doses: $0 \mathrm{~Gy}($ Control $\bullet), 5 \mathrm{~Gy}(\boldsymbol{\nabla}), 10 \mathrm{~Gy}(\boldsymbol{\Delta}), 15 \mathrm{~Gy}(\boldsymbol{\nabla}), 20 \mathrm{~Gy}(\boldsymbol{)})$. In the same developmental stages, embryos were treated with reactor fission neutrons (b) at dose levels

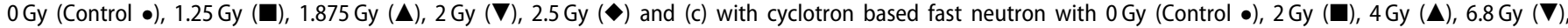
$8.12 \mathrm{~Gy}(\boldsymbol{\vee}), 10.28 \mathrm{~Gy}(\mathrm{o})$. The proportion of viable to total zebrafish embryos were determined at $24,48,72,96,120,144$ and 168 hours post irradiation. Standard errors of the three independent experiments are included in the graphs; ${ }^{* * *} p<.001$ significant differences relative to the control group.
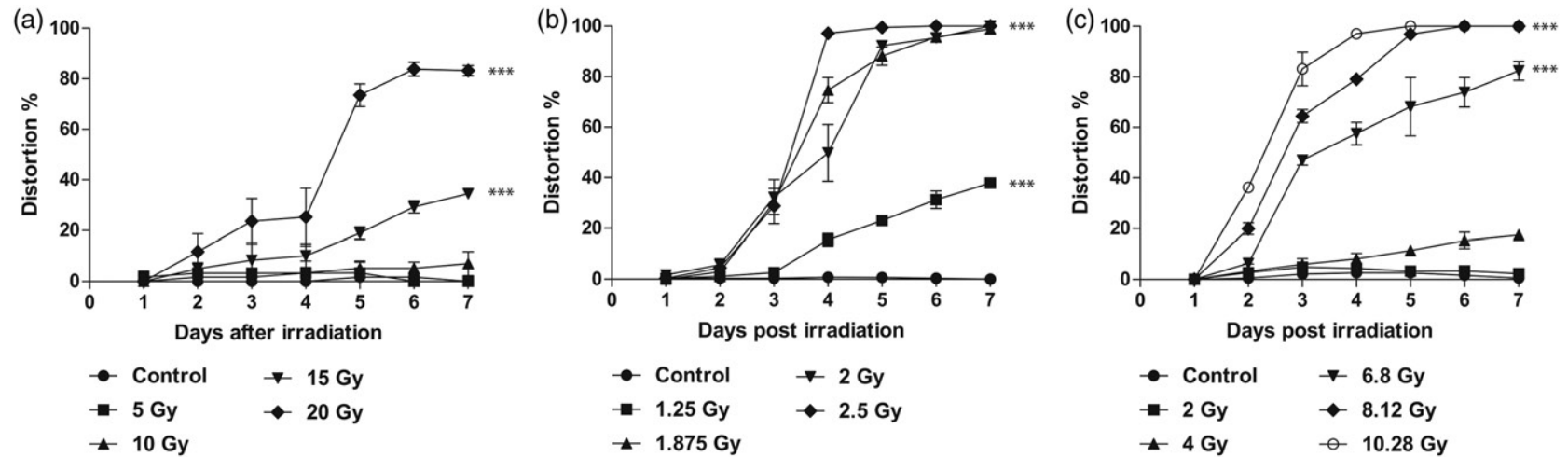

Figure 5. Daily assessment after ionizing radiation treatment induced morphologic changes (spine curvature, pericardial edema and micro-ophthalmia). (a) Embryos exposed to conventional photon with doses: $0 \mathrm{~Gy}$ (Control $\bullet$ ), $5 \mathrm{~Gy}(\boldsymbol{\square}), 10 \mathrm{~Gy}(\mathbf{\Delta}), 15 \mathrm{~Gy}(\boldsymbol{\nabla}), 20 \mathrm{~Gy}(\bullet)$ ). Radiation with reactor fission neutrons (b) at dose levels $0 \mathrm{~Gy}($ Control $\bullet$ ), $1.25 \mathrm{~Gy}(\boldsymbol{\square}), 1.875 \mathrm{~Gy}(\mathbf{\Lambda}), 2 \mathrm{~Gy}(\boldsymbol{\nabla}), 2.5 \mathrm{~Gy}(\bullet)$ and (c) with cyclotron based fast neutron with $0 \mathrm{~Gy}($ Control $\bullet$ ), $2 \mathrm{~Gy}(\mathbf{\square}), 4 \mathrm{~Gy}(\mathbf{\Lambda})$, $6.8 \mathrm{~Gy}(\boldsymbol{\nabla}), 8.12 \mathrm{~Gy}(\boldsymbol{\vee}), 10.28 \mathrm{~Gy}(\circ)$. The proportion of malformation rate were determined to total number of living embryos up to 7 days post irradiation. Results shows the represent mean \pm SD of triplicate experiments.

embryos increased the uncertainty of the malformation analysis.

\section{Histopathological evaluation}

The eye, brain, the gastrointestinal system, liver and muscles were analyzed in order to determine the radiation response of the different tissue type. The histopathological assessment showed tissue alteration in different organs of the embryos. Micro-ophthalmia and microcephaly were observed postirradiation and are the result of the downregulation of cyclin D1 protein (Duffy et al. 2005). The volume of the eyes and its layers structure were marked in the coronal sections of the survived embryos at 168 hour post-treatment with different radiation qualities. Several sections were prepared from every embryo and the maximum width of eyes was measured. For evaluation the largest eye-diameter sections, where the lens was in the same plane, was chosen from each treatment group (control and irradiated) and contrasted. The cellular organization in the normal untreated zebrafish embryo retina is as follows: ganglion cell layer ( $\mathrm{gcl})$, inner plexiform layer (ipl), inner nuclear layer (inl), outer plexiform layer (opl), outer nuclear layer (onl), retinal pigmented epithelium (rpe) (Figure 6(a)). The different type of ionizing radiation treatment caused considerably disorganization of the retinal layers, in contrast to these separable cellular layers. The inner and outer plexiform layer (ipl, opl) was difficult to distinguish or nearly absent (Figure 6(b-d)), white arrows) or in some individuals completely disappeared. It was difficult to distinguish most of the remaining cellular layers, especially the two cell layers previously mentioned. The retinal pigmented epithelium (rpe) was specifically thickened in case of both photon (Figure 6(b)) and cyclotron based neutron irradiation (Figure 6(d)). The shape of the cells and its layers showed a major alteration after irradiation, the prominent round nuclei of the inner and outer nuclear layer as well as the ganglion cell layer could not be discerned. All of these cellular changes were more prominent with increased dose levels.

The radiation resulted in lens opacification and the loss of volume (Figure $6(c, d)$ ), white triangle) with a marked decrease in the diameter of the eye $200.58 \pm 21 \mu \mathrm{m}$ was in case of photon irradiation, $210.98 \pm 32 \mu \mathrm{m}$ and $159.43 \pm 12 \mu \mathrm{m}$ 

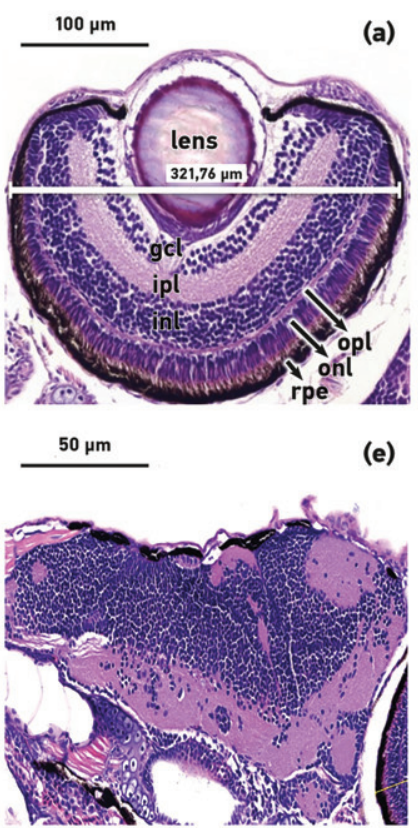

$100 \mu \mathrm{m}$



$50 \mu \mathrm{m}$



(b)

(f)
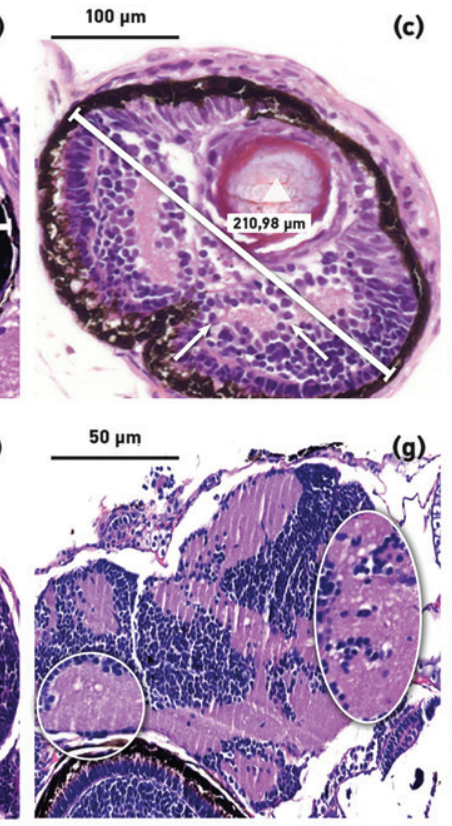
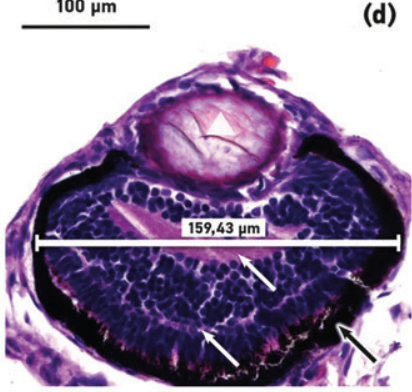

$50 \mu \mathrm{m}$

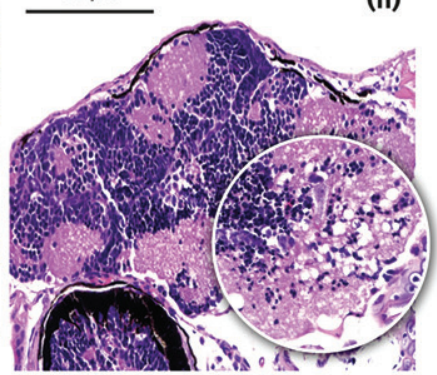

Figure 6. The effects of ionizing radiation of the eye and the developing central nervous system in zebrafish embryos. Representative H\&E stained images of the eyes ((a) control, (b) photon $20 \mathrm{~Gy}$, (c) fission neutron $2 \mathrm{~Gy}$, (d) cyclotron based neutron $8.12 \mathrm{~Gy}$ ) and the cranial structures of the brain ((e) control, (f) photon $20 \mathrm{~Gy},(\mathrm{~g})$ fission neutron $2 \mathrm{~Gy}$, (h) cyclotron based neutron $8.12 \mathrm{~Gy}$ ) of representative surviving zebrafish embryos at $168 \mathrm{hpf}$ after exposure. Figure (a) shows the different layers: lens, ipl and opl, inner and outer plexiform layer; gcl, ganglion cell layer; inl and onl, inner and outer nuclear layer; rpe, retinal pigmented epithelium. (20× magnification, scale bar $100 \mu \mathrm{m}$ ). The eye of the irradiated embryos shows a decrease in volume as well as the loss of structuring of the various layers. The eye of the neutron beams treated embryos shows loss of the lens volume and opacification of its ((c), (d) white triangle), other structures such as inner and outer plexiform layer (b-d) white arrows) are difficult to distinguish or disappeared. The retinal pigmented epithelium shows thickening ((b), (d) black arrows). The cranial sections of the treated and survived embryos at $168 \mathrm{hpf}$ after radiation treatment ((e) control, (f) photon $20 \mathrm{~Gy}$, (g) fission neutron $2 \mathrm{~Gy}$, (h) cyclotron based neutron $8.12 \mathrm{~Gy})$. The treated embryos brain showed tissue disorganization in medulla and in the optic chiasm ((g) white circle). There was a reduction in the level of the cell organization in the diencephalon ( $(\mathrm{f})$ white circle) and in the medulla ((h)- white circle) in the observed individuals exposed with photon and cyclotron based neutron sources. $40 \times$ magnification, scale bar $50 \mu \mathrm{m}$.

in embryos irradiated with fission neutron and cyclotron based neutron sources, compared to the unirradiated $321.76 \pm 23 \mu \mathrm{m}$ (Figure 6(a-d)).

The neuropil is intact for the mock irradiated embryos brain with no neuropil loosening observed unlike in $20 \mathrm{~Gy}$ photon, 2Gy groups using fission neutron and $8.12 \mathrm{~Gy}$ treated groups with cyclotron based neutron sources. The low dose irradiation caused mild oedema in several observed individuals brain, independent of the radiation and pronounced cytotoxic oedema and neuropil vacuolization were detected in groups irradiated with higher doses. Cell disorganization was found in the diencephalon (Figure 6(f) white circle) 7 days after the treatment and in the medulla (Figure 6(h) white circle) in the observed individuals exposed to $20 \mathrm{~Gy}$ photon and $8.12 \mathrm{~Gy}$ cyclotron based neutron sources. The brain showed cellular disorganization (neuropil vacuolization) in medulla (Figure 6(g) white circle) and less perturbation in case of fission neutron irradiation with $2 \mathrm{~Gy}$ dose. In the irradiated brains, the photographed plane was chosen where the most pronounced changes were observed.

In observed individuals, the contrast with the mock irradiated samples the intestinal surfaces were retained and radiation led to gastrointestinal system tissue disorganization and subsequent micro-erosion. The number of goblet cells partial decrease in the groups irradiated with $20 \mathrm{~Gy}$ photon and $2 \mathrm{~Gy}$ fission neutron (Figure $7(\mathrm{~b}, \mathrm{c})$ ) or almost complete depletion of in case of cyclotron based neutron at $8.12 \mathrm{~Gy}$ dose level (Figure $7(d)$ ).
Histological analysis showed dose-dependent lesions in the liver, tissue loosening and disorganization were observed in the treated groups (Figure $7(b-d)$ ) white circle). Figure $7(c, d)$ shows that in the neutron irradiation group's aggressive necrosis in the hepatocytes were also observed.

Finally, the histopathologic effects of different radiation qualities on the zebrafish muscle were determined. In each neutron irradiated group, hypereosinophilic necrotic musclefibers, aggressive necrosis were detected (Figure $7(b-d)$ ).

Microscopic examination revealed that the tissue alterations appeared to be dose-dependent in the different organ systems. Assessing the different tissue changes in the gastrointestinal mucosa, the cell lines were unsettled, the cells stained darkly and the nuclei are not basally located. The goblet cells particularly showed early signs of the effects of radiation. The goblet cell number seemed to be well correlated to the delivered dose and could be a reliable marker for quantitative assessment of acute radiation. The muscle and liver tissue shows irreversible changes at early time intervals after irradiation. The tissue damages caused by high LET radiation was more pronounced at the same dose level corresponded to $\mathrm{LD}_{50}$ dose equivalent and it underlines the importance of an endpoint definition for RBE calculation. Dose-response difference was observed in the extent of oedema. This detailed descriptive analysis on histopathological changes provide a good basis for establishment of quantitative evaluation on the acute and subacute dose-dependent micro-morphological deteriorations and for the detection of late tissue damages. 
Control


20 Gy- photon (6 MV)
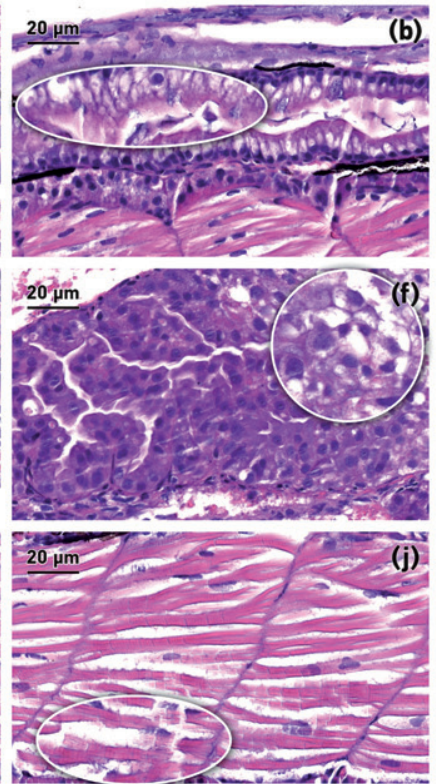

2 Gy- fission neutron $<E n=1 \mathrm{MeV}>$

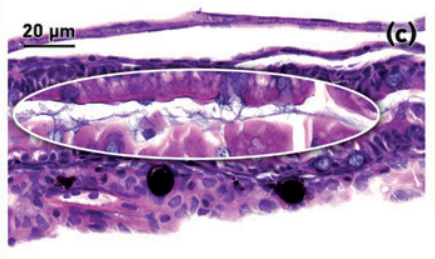

$8.12 \mathrm{~Gy}-$ cyclotron neutron $(\mathrm{p}(18 \mathrm{MeV})+\mathrm{Be}$, $<\mathrm{En}>=3.5 \mathrm{MeV}$ )
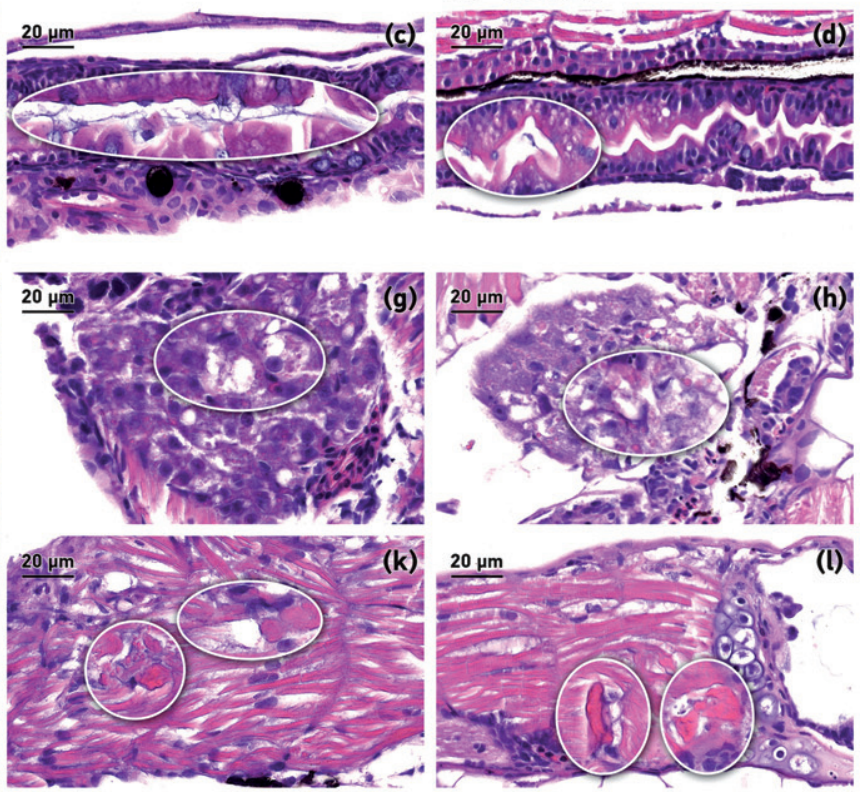

Figure 7. Different tissue radiation-induced alterations. Representative sagittal sections of the intestinal tract (a-d), liver (e-h) and the muscle (i-l) from zebrafish embryos treated. There is a reduction in the number of goblet cells in the gastrointestinal system in all irradiated groups irrespectively of the radiation type (b-d) beaded sections). In ( $\mathrm{f}-\mathrm{h}$ ) white circles indicates tissue loosening, cell disorganization and hepatocytes necrosis (c) in the liver. (j-l) circle marked shows hypereosinophilic muscle-fibers and aggressive necrosis in the muscle. All images have an $80 \times$ magnification and scale bar is $50 \mu \mathrm{m}$.

\section{Discussion}

The increasing use of particle therapy and the emergence of innovative radiation methods raise the necessity of valid, reproducible preclinical data on the biological effects of these ionizing radiations. Thus, it is of great importance and relevance to define the $\mathrm{RBE}$, the ratio between the reference photon and the experimental beam doses resulting in a biological isoeffect, - one of the traditionally defined parameter of a new radiation quality. Paramount experiments have been conducted in order to measure the RBE at different high LET sources at particle accelerator facilities worldwide using in vitro cell cultures, the gold standard of radiobiology (Kuhne et al. 2009; Beyreuther et al. 2009; Jones et al. 2011; Seth et al. 2014; Baiocco et al. 2016; Jones 2016). The RBE is known to be variable and influenced by different factors such as tissue type, biological endpoint, treatment regimen, ion type (Lühr et al. 2017). In order to overcome the uncertainties of the in vitro experiments, in vivo systems that are clinically more relevant have been introduced in radiation research providing important data on the dose-dependent reactions of a complex organism. One of the well-established rodent model is the murine acute upper intestinal crypt regeneration test (Gueulette et al. 2001) which was used extensively for RBE definition and for inter-comparison of the biological effectiveness of different facilities generating fast neutrons, epithermal neutrons based BNCT and proton beams. Further acute radiation effects are assessed using the rodent lung pneumonitis assay, delayed skin reaction scoring and rat spinal cord damage (assessed by hind leg motion depletion), mouse skin and kidney irradiation (Joiner 1989; Bijl et al. 2002; Uzawa et al. 2007; Lühr et al. 2017).
These rodent model-based tests proved to be reproducible, reliable for quantitative assessment of the biological effectivity of high LET radiation with changing parameters (dose rate, fractionation) and for inter-comparison of different non-conventional facilities and specific biological properties of different ion species e.g. helium, carbon, neon, silicon or argon ions (Joiner et al. 1983; Dokic et al. 2016). However, small animal experiments have become increasingly more expensive and complicated from organization (transportation, local maintenance), ethical and radiation performance and, in particular, if a novel radiation approach should be investigated in an early developmental phase with several parametric restrictions. The development of a less vulnerable, less expensive novel in vivo vertebrate model, which fulfills the requirements drawn up by E. J. Hall 40 years ago (Hall and Kellerer 1979) to be a 'convenient, portable and reproducible' biological system for inter-comparison, is essential for studies on emerging radiation modalities. The fish embryo system has become a popular model for several preclinical research areas such as cardiovascular, neurological, pharmacological, developmental and medical sciences. The vertebrate model was proposed first by Japanese groups using the medaka (Oryzias latipes) as intact living organism to investigate nonconventional radiation which provides highly relevant simultaneous information regarding radiation injuries at the molecular, cell tissue and whole organism levels (Shima and Shimada 1988, 1991). Later radiobiology research with fish embryo systems included studies on radioprotection aspects (Kuhne et al. 2009); adaptive response; bystander and abscopal effects and radiation modifiers (McAleer et al. 2005; Geiger et al. 2006; Daroczi et al. 2009; Wang et al. 2011; Epperly et al. 2012; $\mathrm{Ng}$ et al. 2015; $\mathrm{Ng}$ et al. 2016; 
Szabó et al. 2016). Few reports have been published on neutron RBEs using fish embryo model by assessment of different end points. Shima and Shimada (1991) introduced specific locus mutation assay in germ cell lines for measuring the RBE of fission neutrons resulting a value in between 3 and 7, using the Japanese medaka fish embryos. Takai et al. 2004 published dose and time-dependent responses for micronucleus induction in gill cells of medaka with irradiation of X-rays and fast neutrons defining an RBE of $4.3 \pm 0.6$. Kuhne et al. (2009) measured by imaging the apoptotic cells in the tail region the RBE of cosmic neutrons in a wide range of potential neutron energies.

The aim of RBE definition of high LET beams resulted in the use of two quantitative endpoints (survival and malformation) and a detailed tissue damage histological analysis using another fish species. In line with cell culture, mice intestinal crypt regeneration test and results obtained using other mammalian models for fast neutron beams, the RBE defined by zebrafish embryo survival, increases with decreasing neutron energy (from -2.5 for $p(18 \mathrm{MeV})+B e$ to -10 for $1 \mathrm{MeV}$ fission neutrons). The energy dependence of biological effect of neutron beams is well known (Hall et al. 1975; Field 1976) and the maximum relative biological effectiveness (RBE) is found for energies $\sim 1 \mathrm{MeV}$. However, the exact RBE number at a certain energy level is highly influenced by the biological system used, the defined endpoint, the dose, depth and many other factors. A strong neutron energy dependence was also found, in line with literature data.

In our experiment, the $1 \mathrm{MeV}$ mean energy mixed neutron-photon beam proved to be 4 times more effective biologically than the $18 \mathrm{MeV}$ mean energy mixed neutronphoton radiation. After the introduction of fast neutron therapy in the sixties, numerous experiments have proven that higher energy neutrons caused less cellular damages, resulting in decreasing RBE in correlation to increasing neutron energies (Bateman et al. 1961; Hall et al. 1975; Field 1976).

Recent calculations on neutron transport with track structures up to DNA damage induction at different neutron energy levels have provided a better understanding on the physical and biochemical mechanism and have resulted in strong correlation of the RBE to neutron energy (Baiocco et al. 2016). The result of the calculated values were well supported by the experiments performed using broad energy spectra, mixed neutron-photon and monoenergetic neutron beams (Juerß et al. 2017).

The high reliability of the zebrafish embryo survival assay was revealed during the repeated experiments and the $L_{50}$ definition of the $24 \mathrm{hpf}$ embryos has strong agreement with the radiobiology literature (McAleer et al. 2005; Daroczi et al. 2006; Geiger et al. 2006; Szabó et al. 2016). Therefore, survival analysis for a certain age of the zebrafish embryos can be considered as an appropriate tool for the RBE measurements and for studies on the effects of radiation modifiers. There were no major differences in the distortion analysis on the $4^{\text {th }}$ and $5^{\text {th }}$ day post-irradiation but the morphologic change evaluation could be refined in future experiments by increasing the time points of malformation evaluation on the $4^{\text {th }}$ and $5^{\text {th }}$ day ( $8 \mathrm{~h}$ or $12 \mathrm{~h}$ intervals) and/or by measuring and quantifying the different organ perturbations separately e.g. spine curvature, developmental deteriorations (body growth, eye development) and edematous changes of the pericardium and the yolk sac.

Detected microscopic changes (marked cellular changes in eyes, brain, liver, muscle and in the gastrointestinal system) were more pronounced at higher dose levels and at higher LET radiations similar to the results of the survival comparison. Other authors have also evaluated histopathological changes of the zebrafish embryo system due to ionizing radiation for investigation of radio-protector agent (Daroczi et al. 2006; Geiger et al. 2006). They characterized the radio-protective effect of amifostine by the survival test and analyzed the changes in the brain and eye using 2, 4, 6, 8, $24 \mathrm{hpf}$ embryos finding strong correlation of the histo-morphological changes to increased cellular death. All of the investigated tissues in the literature, the tail muscle, intestinal tract and central nervous system and eye exhibited clearly identifiable radiation-related alterations, i.e. hypocellularity and disorganization of cellular layers in concordance with these findings.

\section{Conclusions}

The zebrafish embryo system has been proved to be a convenient, highly reproducible versatile model for assessing the effect of ionizing radiation with different LET. Viability detection has been shown to be a reproducible and responsive measure for all radiation types measured. Further powerful endpoints are under development including the promising quantitative assessments of the morphological deterioration and histopathological changes.

\section{Disclosure statement}

No potential conflict of interest was reported by the authors.

\section{Funding}

The ELI-ALPS project (GINOP-2.3.6-15-2015-00001) is supported by the European Union and co-financed by the European Regional Development Fund. In part, this work was supported by the European Regional Development Fund and Hungary in the frame of the project GINOP-2.2.1-15-2016-00012. The project has received funding from the European Union's Horizon 2020 research and innovation programme under grant agreement no 654148 Laserlab-Europe

\section{Notes on contributors}

Emília Rita Szabó is a last-year PhD student at the ELI-HU Nonprofit Ltd. in collaboration with the University of Szeged. She received a master's degree in biology from the University of Cluj-Napoca, Romania. Her current research field is the establishment of the zebrafish embryo model to study the effects of different radiation qualities and definition of the RBE.

Zita Reisz is a resident pathologist at the Department of Pathology, University of Szeged. She received her master's degree in medicine from the University of Szeged. She is involved in university education and her speciality is neuropathology as well as his research field is the histological diagnosis of CNS tumors. 
Róbert Polanek is a first-year PhD student at the ELI-HU Nonprofit Ltd. in collaboration with the University of Szeged. He received a master's degree in physics from the University of Cluj-Napoca, Romania. His current research field is the establishment of different dosimetry systems.

Tünde Tökés is a postdoctoral researcher at the ELI-HU Nonprofit Ltd. She received a master's degree in biology and got her $\mathrm{PhD}$ degree in Graduate School of Multidisciplinar Medical Sciences from the University of Szeged, Hungary. Her research topic is the investigation of the acute and late consequences of irradiation.

Szabolcs Czifrus is an associate professor and director of Institute of Nuclear Techniques at Budapest University of Technology and Economics. He received a master's degree in physics from the Eötvös Loránd University of Sciences. His research area is IV. reactor physics of generation reactors, Monte Carlo particle transport methods, nuclear fuel cycle.

Csilla Pesznyák is an associate professor at the Institute of Nuclear Techniques at Budapest University of Technology and Economics. She received her master's degree in physics from the Faculty of Natural Sciences and Mathematics of the University of Novi Sad, and got her biomedical engineer $\mathrm{PhD}$ degree from Semmelweis University, Budapest. Her field of research is radiotherapy, including teletherapy irradiation techniques, dosimetry, quality assurance, radiation biology, radiation protection and education organization.

Barna Biró is a junior research fellow at the Hungarian Academy of Sciences Institute for Nuclear Research (MTA Atomki), Debrecen, Hungary. He received a master's degree in physics from the University of Cluj-Napoca, Romania. His current research field is the exploration and development of a novel control software framework for research infrastructures.

András Fenyvesi is a senior research associate, head of organizational unit at the laboratory of cyclotron applications. His current research topic is neutron physics, industrial and medical applications. Projects in which he participates: National Nuclear Research Program of Hungary, Complex Innovation - health industry network for efficiency improvement, exploration and development of a novel control software framework for research infrastructures, CMS experiment of the Large Hadron Collider in Hungary.

Beata Király is a research associate at the Hungarian Academy of Sciences Institute for Nuclear Research (MTA Atomki), Debrecen, Hungary. Her field of research is the Central Nervous System Imaging, health industry network for efficiency improvement and exploration as well as development of a novel control software framework for research infrastructures.

József Molnár is a senior research associate and technical director at the Hungarian Academy of Sciences Institute for Nuclear Research (MTA Atomki), Debrecen, Hungary. His current research field is the experimental particle physics, measurement of radiation tolerance, detector developments, study of infrared in the vicinity of interferometric gravity wave detectors and surveying chemical processes on the surface with positron emissive tomography.

Szilvia Brunner is a first-year PhD student at the ELI-HU Nonprofit Ltd. in collaboration with the University of Szeged. She received a master's degree in biology from the University of Szeged, Hungary. Her current research field is the examination of the acute effects of irradiation.

Borbála Daroczi is a research associate, at the Department of Internal Medicine, Division of Geriatrics, University of Debrecen, Hungary. She received her master's degree in medicine from the University of Debrecen, and got her PhD degree in Doctoral School of Clinical Medicine from the University of Szeged. Her current research field is the evaluation of agents that can modify the radiation response.

Zoltán Varga is a scientific associate, physicist at the Department of Oncotherapy, University of Szeged. He received a master's degree in physics, and PhD degree from the University of Szeged. His current research field is radiation therapy, dosimetry.
Katalin Hideghéty is associate professor at the Department of Oncotherapy, University of Szeged and a group leader at the ELI-HU Nonprofit Ltd. in Hungary. She received her master's degree in medicine from the University of Szeged, and got her PhD degree from University of Pécs and her habilitation was performed at University Szeged. Her research field is the optimization of radiotherapy for brain, skin, head and neck and gastrointestinal tumors both in clinical studies and in preclinical investigations, with special focus on novel techniques such as laser driven ionizing radiation, BNCT, microbeam RT, and hadron therapy.

\section{References}

Ainsbury EA, Barnard S, Bright S, Dalke C, Jarrin M, Kunze S, Tanner R, Dynlacht JR, Quinlan RA, Graw J, et al. 2016. Ionizing radiation induced cataracts: recent biological and mechanistic developments and perspectives for future research. Mutat Res. 770:238-261.

Allemani C, Weir HK, Carreira H, Harewood R, Spika D, Wang X-S, Bannon F, Ahn JV, Johnson CJ, Bonaventure A and CONCORD Working Group. 2015. Global surveillance of cancer survival 19952009: analysis of individual data for 25,676,887 patients from 279 population-based registries in 67 countries (CONCORD-2). Lancet. 385:977-1010.

Amatruda JF, Shepard JL, Stern HM, Zon LI. 2002. Zebrafish as a cancer model system. Cancer Cell. 1:229-231.

Baiocco G, Barbieri S, Babini G, Morini J, Alloni D, Friedland W, Kundrát P, Schmitt E, Puchalska M, Sihver L, et al. 2016. The origin of neutron biological effectiveness as a function of energy. Sci Rep. 6:34033.

Barth RF, Vicente MGH, Harling OK, Kiger WS, Riley KJ, Binns PJ, Wagner FM, Suzuki M, Aihara T, Kato I. 2012. Current status of boron neutron capture therapy of high grade gliomas and recurrent head and neck cancer. Radiat Oncol. 7:146.

Bateman JL, Rossi HH, Bond VP, Gilmartin J. 1961. The dependence of RBE on energy of fast neutrons. 2. Biological evaluation of discrete neutron energies in the range 0.43 to $1.80 \mathrm{Mev}$. Radiat Res. 15:694-706.

Beyreuther E, Dörr W, Lehnert A, Lessmann E, Pawelke J. 2009. Relative biological effectiveness of 25 and $10 \mathrm{kV}$ X-rays for the induction of chromosomal aberrations in two human mammary epithelial cell lines. Radiat Environ Biophys. 48:333-340.

Bijl HP, van Luijk P, Coppes RP, Schippers JM, Konings AWT, van der Kogel AJ. 2002. Dose-volume effects in the rat cervical spinal cord after proton irradiation. Int J Radiat Oncol Biol Phys. 52:205-211.

Bräuer-Krisch E, Adam J-F, Alagoz E, Bartzsch S, Crosbie J, DeWagter C, Dipuglia A, Donzelli M, Doran S, Fournier P, et al. 2015. Medical physics aspects of the synchrotron radiation therapies: microbeam radiation therapy (MRT) and synchrotron stereotactic radiotherapy (SSRT). Phys Med. 31:568-583.

Broerse JJ, Mijnheer BJ, Williams JR. 1981. European protocol for neutron dosimetry for external beam therapy. European Clinical Neutron Dosimetry Group (ECNEU). Br J Radiol. 54:882-898.

Daroczi B, Kari G, McAleer MF, Wolf JC, Rodeck U, Dicker AP. 2006. In vivo radioprotection by the fullerene nanoparticle DF-1 as assessed in a zebrafish model. Clin Cancer Res. 12:7086-7091.

Daroczi B, Kari G, Ren Q, Dicker AP, Rodeck U. 2009. Nuclear factor kappaB inhibitors alleviate and the proteasome inhibitor PS-341 exacerbates radiation toxicity in zebrafish embryos. Mol Cancer Ther. 8:2625-2634.

Dokic I, Mairani A, Niklas M, Zimmermann F, Chaudhri N, Krunic D, Tessonnier T, Ferrari A, Parodi K, Jäkel O, et al. 2016. Next generation multi scale biophysical characterization of high precision cancer particleradiotherapy using clinical proton, helium-, carbon- and oxygen ion beams. Oncotarget. 7:56676-56689.

Duffy KT, McAleer MF, Davidson WR, Kari L, Kari C, Liu C-G, Farber SA, Cheng KC, Mest JR, Wickstrom E, et al. 2005. Coordinate control of cell cycle regulatory genes in zebrafish development tested by cyclin D1 knockdown with morpholino phosphorodiamidates and hydroxyprolyl-phosphono peptide nucleic acids. Nucleic Acids Res. 33:4914-4921. 
Epperly MW, Bahary N, Quader M, Dewald V, Greenberger JS. 2012. The zebrafish-Danio rerio-is a useful model for measuring the effects of small-molecule mitigators of late effects of ionizing irradiation. In Vivo. 26:889-897.

Fenyvesi András. 2004. Neutron sources for basic and applied research at the MGC-20E cyclotron of atomki proceedings of the enlargement workshop on neutron measurements and evaluations for applications NEMEA. Budapest (HU): Centre Institute for Reference Materials and Measurements.

Field SB. 1976. An historical survey of radiobiology and radiotherapy with fast neutrons. Curr Top Radiat Res Q. 11:1-86.

Geiger GA, Parker SE, Beothy AP, Tucker JA, Mullins MC, Kao GD. 2006. Zebrafish as a "biosensor"? Effects of ionizing radiation and amifostine on embryonic viability and development. Cancer Res. 66:8172-8181.

Gueulette J, Slabbert JP, Böhm L, De Coster BM, Rosier JF, OctavePrignot M, Ruifrok A, Schreuder AN, Wambersie A, Scalliet $P$, et al. 2001. Proton RBE for early intestinal tolerance in mice after fractionated irradiation. Radiother Oncol. 61:177-184.

Hall EJ, Novak JK, Kellerer AM, Rossi HH, Marino S, Goodman LJ. 1975. RBE as a function of neutron energy. I. Experimental observations. Radiat Res. 64:245-255.

Hall EJ, Kellerer A. 1979. Review of RBE data for cell in culture. In Barendsen GW, Broerse J, Breur K, editors. High LET radiations in clinical radiotherapy. Headington Hill Hall, Oxford OX3 OBW, England: Pergamon Press Ltd; p. 171-174.

Hamada N, Sato T. 2016. Cataractogenesis following high-LET radiation exposure. Mutat Res. 770:262-291.

Hwang M, Yong C, Moretti L, Lu B. 2007. Zebrafish as a model system to screen radiation modifiers. Curr Genomics. 8:360-369.

Joiner MC, Maughan RL, Fowler JF, Denekamp J. 1983. The RBE for mouse skin irradiated with $3-\mathrm{MeV}$ neutrons: single and fractionated doses. Radiat Res. 95:130-141.

Joiner M. 1989. A comparison of the effects of $p(62)+B e$ and $d(16)+B e$ neutrons in mouse kidney Radiother Oncol. 13:211-214.

Jones B. 2016. Why RBE must be a variable and not a constant in proton therapy. Br J Radiol. 89:20160116.

Jones B, Dale RG, Deehan C, Hopkins KI, Morgan DA. 2001. The role of biologically effective dose (BED) in clinical oncology. Clin Oncol (R Coll Radiol). 13:71-81.

Jones B, Underwood TS, Carabe-Fernandez A, Timlin C, Dale RG. 2011 Fast neutron relative biological effects and implications for charged particle therapy. Br J Radiol. 1:11-18.

Juerß D, Zwar M, Giesen U, Nolte R, Kriesen S, Baiocco G, Puchalska M, van Goethem MJ, Manda K, Hildebrandt G. 2017. Comparative study of the effects of different radiation qualities on normal human breast cells. Radiat Oncol. 12:159.

Kuhne WW, Gersey BB, Wilkins R, Wu H, Wender SA, George V, Dynan WS. 2009. Biological effects of high-energy neutrons measured in vivo using a vertebrate model. Radiat Res. 172:473-480.

Langheinrich U. 2003. Zebrafish: a new model on the pharmaceutical catwalk. Bioassays. 9:904-912.

Liao JJ, Parvathaneni U, Laramore GE, Thompson JA, Bhatia S, Futran ND, Bhrany AD, Hawes SE, Ladra M. 2014. Fast neutron radiotherapy for primary mucosal melanomas of the head and neck. Head Neck. 36:1162-1167.

Lühr A, von Neubeck C, Helmbrecht S, Baumann M, Enghardt W, Krause M. 2017. Modeling in vivo relative biological effectiveness in particle therapy for clinically relevantendpoints. Acta Oncol. 56:1392-1398.

McAleer MF, Davidson C, Davidson WR, Yentzer B, Farber SA, Rodeck U, Dicker AP. 2005. Novel use of zebrafish as a vertebrate model to screen radiation protectors and sensitizers. Int J Radiat Oncol Biol Phys. 61:10-13.
Medin PM, Foster RD, van der Kogel AJ, Sayre JW, McBride WH, Solberg TD. 2011. Spinal cord tolerance to single-fraction partial-volume irradiation: a swine model. Int J Radiat Oncol Biol Phys. 79:226-232.

$\mathrm{Ng} \mathrm{CY}$, Kong EY, Kobayashi A, Suya N, Uchihori Y, Cheng SH, Konishi T, Yu KN. 2016. Non-induction of radioadaptive response in zebrafish embryos by neutrons. J Radiat Res. 57:210-219.

Ng CYP, Kong EY, Kobayashi A, Suya N, Uchihori Y, Cheng SH, Konishi T, Yu KN. 2015. Neutron induced bystander effect among zebrafish embryos. Radiat Phys Chem. 117:153-159.

Peeters A, Grutters JP, Pijls-Johannesma M, Reimoser S, De Ruysscher D, Severens JL, Joore MA, Lambin P. 2010. How costly is particle therapy? Cost analysis of external beam radiotherapy with carbon-ions, protons and photons. Radiother Oncol. 95:45-53.

Schüler E, Eriksson K, Hynning E, Hancock SL, Hiniker SM, BazalovaCarter M, Wong T, Le QT, Loo BW Jr, Maxim PG. 2017. Very highenergy electron (VHEE) beams in radiation therapy; treatment plan comparison between VHEE, VMAT, and PPBS. Med Phys. 44:2544-2555.

Seth I, Schwartz JL, Stewart RD, Robert Emery R, Joiner MC, Tucker JD. 2014. Neutron exposures in human cells: bystander effect and relative biological effectiveness. PLoS One. 9:98947.

Shima A, Shimada A. 1988. Induction of mutations in males of the fish Oryzias latipes at a specific locus after gamma-irradiation. Mutat Res. 198:93-98.

Shima A, Shimada A. 1991. Development of a possible nonmammalian test system for radiation-induced germ-cell mutagenesis using a fish, the Japanese medaka (Oryzias latipes). Proc Natl Acad Sci USA. 88:2545-2549.

Specht HM, Neff T, Reuschel W, Wagner FM, Kampfer S, Wilkens JJ, Petry W, Combs SE. 2015. Paving the road for modern particle therapywhat can we learn from the experience gained with fast neutron therapy in Munich?. Front Oncol. 5:262.

Szabó ER, Plangár I, Tőkés T, Mán I, Polanek R, Kovács R, Fekete G, Szabó Z, Csenki Z, Baska F, et al. 2016. I-alpha glycerylphosphorylcholine as a potential radioprotective agent in zebrafish embryo model. Zebrafish. 13:481-488.

Takai A, Kagawa N, Fujikawa K. 2004. Dose- and time-dependent responses for micronucleus induction by X-rays and fast neutrons in gill cells of medaka (Oryzias latipes). Environ Mol Mutagen. 44:108-112.

Uzawa A, Ando K, Furusawa Y, Kagiya G, Fuji H, Hata M, Sakae T, Terunuma T, Scholz M, Ritter S, et al. 2007. Biological intercomparison using gut crypt survivals for proton and carbon-ion beams. J Radiat Res. 48:75-80.

Wang C, Smith RW, Duhig J, Prestwich WV, Byun SH, McNeill FE, Seymour CB, Mothersill CE. 2011. Neutrons do not produce a bystander effect in zebrafish irradiated in vivo. Int J Radiat Biol. 87:964-973.

Warenius HM, Britten RA, Peacock JH. 1994. The relative cellular radiosensitivity of 30 human in vitro cell lines of different histological type to high LET $62.5 \mathrm{MeV}$ ( $\mathrm{p}$-.Be1) fast neutrons and $4 \mathrm{MeV}$ photons. Radiother Oncol. 30:83-89.

Yasuda T, Kamahori M, Nagata K, Watanabe-Asaka T, Suzuki M, Funayama T, Mitani H, Oda S. 2017. Abscopal activation of microglia in embryonic fish brain following targeted irradiation with heavy-ion microbeam. ljms. 18:1428.

Yoon DK, Jung JY, Suh TS. 2014. Application of proton boron fusion reaction to radiation therapy: a Monte Carlo simulation study. Appl Phys Lett. 105:223507.

Zon LI. 1999. Zebrafish: a new model for human disease. Genome Res. 9:99-100. 